\title{
AVALIAÇÃO DA ESTABILIDADE DE ARMAZENAMENTO DO NÉCTAR DE MARACUJÁ ENRIQUECIDO COM $\beta$-CICLODEXTRINA
}

\author{
C. A. CÂNDIDO FILHO ${ }^{1}$, R. C. BERGAMASCO ${ }^{1}$ \\ ${ }^{1}$ Universidade Estadual de Maringá, Departamento de Engenharia de Alimentos \\ e-mail para contato: rcbergamasco@uem.br
}

\begin{abstract}
RESUMO - Este trabalho teve como objetivo avaliar a estabilidade de armazenamento do néctar de maracujá enriquecido com $\beta$-ciclodextrina ( $\beta$-CD). Foram preparados néctares de maracujá com e sem $\beta-C D$, e armazenados por 30 dias, à temperatura ambiente. Os resultados mostraram que o teor de sólidos solúveis totais das amostras se manteve constante durante o período de armazenamento. A acidez titulável e o pH da amostra controle sofreram alterações, devido a oxidação do ácido ascórbico com o tempo de armazenamento. A amostra enriquecida com $\beta$-CD teve comportamento diferente da amostra controle nestes parâmetros durante o armazenamento, sugerindo uma possível formação de complexo de inclusão entre o ácido ascórbico do néctar e a $\beta-\mathrm{CD}$, protegendo este composto da oxidação. $\mathrm{Na}$ análise de cor, o parâmetro $L^{*}$ foi praticamente constante durante o armazenamento dos néctares, apresentando um aumento de $5 \%$ no néctar enriquecido com $\beta$-CD no fim da estocagem. Uma degradação progressiva das coordenadas $a^{*} \mathrm{e}^{*}$ foi observada nas amostras analisadas, sendo mais acentuada para a amostra enriquecida com $\beta$-CD. Como consequiência, houve uma redução no teor de pró-vitamina $\mathrm{A}$ das amostras, com uma queda de $10 \%$ para a mostra enriquecida com $\beta$-CD na primeira quinzena de estocagem, e 5\% para a amostra controle. Estes dados mostram que o tempo de armazenamento afetou a qualidade nutricional do néctar de maracujá, e a adição de $\beta$-CD não teve um efeito negativo nos parâmetros sob análise.
\end{abstract}

\section{INTRODUÇÃO}

A mudança dos hábitos do consumidor em relação a uma dieta saudável nos últimos anos refletiu em um aumento no consumo de frutas. Enquanto algumas são consumidas frescas, outras são processadas ou preservadas por questões lógicas e econômicas, por necessidades culinárias, ou facilitar o seu uso por certos grupos de consumidores (Navarro et al., 2011b). Em vista disso, o mercado brasileiro de sucos e néctares prontos para beber tem se expandido de forma rápida.

O maracujá amarelo (Passiflora edulis $f$. Flavicarpa) é uma fruta muito cultivada e consumida no Brasil, devido a seus aromas distintos e sabores. Na indústria, ele é processado na 


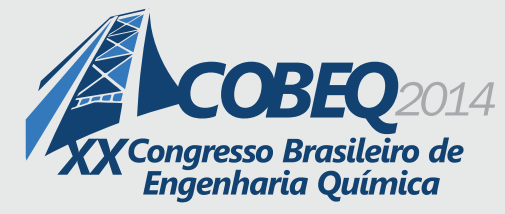

forma de suco integral a $14^{\circ}$ Brix, néctar e suco concentrado a $50^{\circ}$ Brix, além de sorvetes, mousses, bebidas alcoólicas, entre outros (Morzelle et al., 2009).

A cor característica do maracujá amarelo, tanto da casca, como da polpa e do suco, é devido aos carotenóides com atividade de pró-vitamina A e xantofilas, que são tipicamente sensíveis ao oxigênio, calor e luz, e sua estabilidade pode ser influenciada pelo tratamento térmico, condições ambientais e tempo de estocagem (Talcott et al., 2003).

Uma alternativa para reduzir a perda de qualidade do néctar é o uso da técnica de encapsulação por inclusão molecular, utilizando ciclodextrinas. A $\beta$-ciclodextrina $(\beta-C D)$ é um oligossacarídeo cíclico formado por sete unidades de $\mathrm{D}(+)$-glicopiranoses unidas entre si através de ligações $\alpha-(1-4)$. Esta ciclodextrina apresenta uma superfície externa hidrofílica e uma cavidade hidrofóbica, capaz de formar complexo de inclusão com uma variedade de moléculas (Szente \& Szejtli, 2004).

Atualmente, há um crescente número de trabalhos com utilização de ciclodextrinas na área de alimentos, com a finalidade de melhoria de produtos, quanto aos aspectos nutricionais, organolépticos e sensoriais. Estudos têm mostrado diferentes aplicações das ciclodextrinas em sistemas alimentares, como: a) fixação e controle da liberação de aromas; b) modificação do perfil de sabor e odor pelo mascaramento ou remoção dos aromas indesejáveis; c) redução na degradação da cor e desenvolvimento de alimentos funcionais hidrofílicos, tais como sucos e néctares com nutrientes hidrofóbicos (vitaminas, minerais, carotenóides etc) (Szente \& Szejtli, 2004; Navarro et al., 2011b).

Este trabalho teve por objetivo avaliar a estabilidade de armazenamento do néctar de maracujá enriquecido com $\beta$-ciclodextrina. Diferentes parâmetros foram observados durante o armazenamento do produto, tais como sólidos solúveis totais, acidez titulável, $\mathrm{pH}$ e coordenadas CIE L*a*b*.

\section{MATERIAIS E MÉTODOS}

\subsection{Elaboração do néctar}

Para a elaboração do néctar de maracujá, foram utilizados maracujás amarelos (Passiflora edulis f. Flavicarpa) adquiridos em comércio local de Maringá (PR). Inicialmente fez-se a préseleção dos frutos, lavagem e sanitização, corte manual dos frutos e despolpamento. A polpa de maracujá foi filtrada, e adicionada de água e açúcar, até um valor de $12,5^{\circ}$ Brix. Segundo Coelho (2010), valores na faixa de 12 a $14^{\circ}$ Brix são os mais comuns para que o néctar de maracujá esteja com sabor e odor agradável.

O néctar de maracujá foi dividido em duas porções, sendo a primeira, enriquecida com $\beta$ ciclodextrina $(0,9 \%$ p/v; $8 \mathrm{mM})$, e a segunda, sem adição de $\beta-\mathrm{CD}$, considerada como controle. Segundo Özoglu e Baymdirh (2002), a adição de $\beta$-ciclodextrina em sucos de frutas, em 


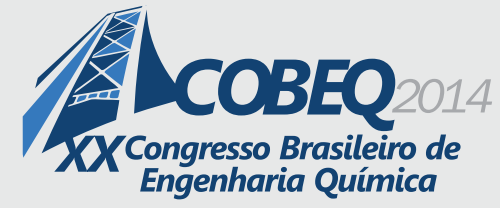

Engenharia Química
19 a 22 de outubro de 2014

Florianópolis/SC

concentrações maiores que $8 \mathrm{mM}$ resulta na redução no "flavor" do suco, devido a complexação com compostos aromáticos, como conseqüência da falta de especificidade da ciclodextrina na fomação de complexos.

Após o preparo dos néctares, estes foram acondicionados em garrafas de vidro transparente, e levados ao tratamento de pasteurização $\left(85^{\circ} \mathrm{C}\right.$, por 30 minutos $)$.

Os néctares foram armazenados a temperatura ambiente, durante um período de 30 dias. Em determinados períodos de tempo, amostras foram coletadas e realizadas análises de sólidos solúveis totais, acidez titulável, $\mathrm{pH}$ e parâmetros de cor.

\subsection{Análises físico-químicas}

O teor de sólidos solúveis totais $\left({ }^{\circ}\right.$ Brix) foi medido por meio de um refratômetro BIOBRIX. A acidez titulável (\% ácido cítrico) foi determinada com solução de hidróxido de sódio $(0,1 \mathrm{M})$ e solução de fenolftaleina (1\%) (IAL 2005). A análise de $\mathrm{pH}$ foi realizada com pHmetro digital PG2000. Todas as análises foram realizadas em triplicata.

\subsection{Análise de cor}

A análise de cor foi determinada em colorímetro digital Konica Minolta Croma Meter CR400, com leituras convertidas para o sistema de cor CIEL*a*b*, onde $\mathrm{L}^{*}$ corresponde à luminosidade, e os parâmetros $\mathrm{a}^{*} \mathrm{e} \mathrm{b}^{*}$ referem-se às coordenadas de cromaticidade verde (-) /vermelho (+) e azul (-)/amarelo (+), respectivamente. Todas as análises foram realizadas em triplicata.

O teor de pró-vitamina A, expresso como equivalentes de retinol (RE), foi estimado matematicamente usando as coordenadas de cor CIE $\mathrm{L}^{*} \mathrm{a}^{*} \mathrm{~b}^{*}$, de acordo com a metodologia descrita por Meléndez-Martínez (2005), por meio da equação (1):

$$
R E=0,308382 . L^{*}+0,108054 . a^{*}+0,337946 . b^{*}+0,004563
$$

\subsection{Análise estatística}

Todos os dados foram submetidos à análise de variância, e as médias comparadas por meio do teste estatístico de Tukey, considerando 95\% de confiança. O software utilizado foi o STATISTICA 6.0, 2007.

\section{RESULTADOS E DISCUSSÃO}

De acordo com os dados da Tabela 1, o tempo de armazenamento e a adição de $\beta$-CD não afetaram significativamente o teor de sólidos solúveis do néctar de maracujá. Porém, o pH e a acidez titulável da amostra controle tiveram uma alteração entre o primeiro e o $30^{\circ}$ dia de 


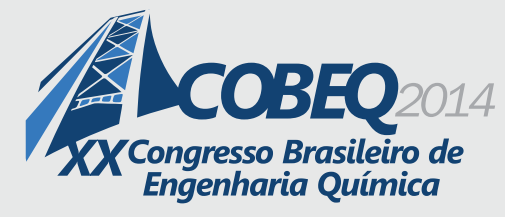

armazenamento, com um aumento no $\mathrm{pH}$ e uma redução na acidez titulável do néctar. Branco et al. (2005) avaliaram a estabilidade fisicoquímica e sensorial de um blend de laranja e cenoura e constataram que a oxidação dos ácidos ascórbico e cítrico do blend, com o tempo e com as condições de armazenamento, poderia justificar a perda de acidez e consequente aumento no $\mathrm{pH}$.

O mesmo resultado não foi observado para a amostra enriquecida com $\beta-C D$, em que não foi notada variação na acidez titulável da amostra em função do tempo de armazenamento. Como a $\beta$-CD tem potencial encapsulante, esta molécula pode ter aprisionado o ácido ascórbico do néctar em sua cavidade, protegendo-o da oxidação. Consequentemente, não houve redução significativa da acidez desta amostra. Todavia, o néctar enriquecido com $\beta$-CD teve um aumento significativo no pH após 15 dias de armazenamento, podendo estar relacionado com a degradação dos carotenóides do néctar.

Tabela 1 - Análise de sólidos solúveis, pH e acidez titulável dos néctares de maracujá armazenados por 30 dias à temperatura ambiente.

\begin{tabular}{c|ccc}
\hline Parâmetro & Tempo (dias) & Controle & Enriquecida com $\beta$-CD \\
\hline Sólidos solúveis & 0 & $12,67 \pm 0,28^{\mathrm{a}, \mathrm{A}}$ & $13,00 \pm 0,25^{\mathrm{a}, \mathrm{A}}$ \\
$\left({ }^{\circ}\right.$ Brix $)$ & 15 & $12,75 \pm 0,00^{\mathrm{a}, \mathrm{A}}$ & $12,75 \pm 0,00^{\mathrm{a}, \mathrm{A}}$ \\
& 30 & $13,00 \pm 0,00^{\mathrm{a}, \mathrm{A}}$ & $13,08 \pm 0,14^{\mathrm{a}, \mathrm{A}}$ \\
\hline $\mathrm{pH}$ & 0 & $3,13 \pm 0,03^{\mathrm{a}, \mathrm{A}}$ & $3,17 \pm 0,06^{\mathrm{a}, \mathrm{A}}$ \\
& 15 & $3,22 \pm 0,06^{\mathrm{a}, \mathrm{b}, \mathrm{A}}$ & $3,34 \pm 0,06^{\mathrm{b}, \mathrm{A}}$ \\
& 30 & $3,31 \pm 0,04^{\mathrm{b}, \mathrm{A}}$ & $3,42 \pm 0,00^{\mathrm{b}, \mathrm{B}}$ \\
\hline Acidez titulável & 0 & $6,99 \pm 1,64^{\mathrm{a}, \mathrm{A}}$ & $5,48 \pm 1,69^{\mathrm{a}, \mathrm{A}}$ \\
$(\%$ ácido cítrico $)$ & 15 & $4,76 \pm 0,40^{\mathrm{a}, \mathrm{b}, \mathrm{A}}$ & $5,42 \pm 0,22^{\mathrm{a}, \mathrm{A}}$ \\
& 30 & $4,18 \pm 0,11^{\mathrm{b}, \mathrm{A}}$ & $4,96 \pm 0,22^{\mathrm{a}, \mathrm{A}}$ \\
\hline
\end{tabular}

Letras minúsculas iguais na mesma coluna e maiúsculas iguais na mesma linha não diferem entre si estatisticamente, ao nível de significância de $5 \%$.

Nas Figuras 1 e 2 são apresentados os resultados de cor dos néctares armazenados a temperatura ambiente, durante 30 dias.

Os néctares de maracujá tiveram uma ligeira redução na luminosidade (Figura 1) na primeira semana de estocagem, permanecendo praticamente constante para a amostra controle durante o período restante de estudo. Porém, para a amostra enriquecida com $\beta$-CD, após este período inicial, observou-se uma variação significativa na luminosidade, resultando num aumento de, aproximadamente, $6 \%$ na coordenada $L^{*}$ após os 30 dias de armazenamento.

Segundo Sandi et al. (2004), compostos resultantes das reações de escurecimento não enzimático e oxidação do ácido ascórbico ou precipitação de pigmentos, contribuem para a redução da luminosidade, dando uma aparência mais escura ao suco. Os autores relatam também que o aumento na luminosidade pode ser causado pela destruição da estrutura de carotenóides, fornecendo uma cor mais clara ao produto. 


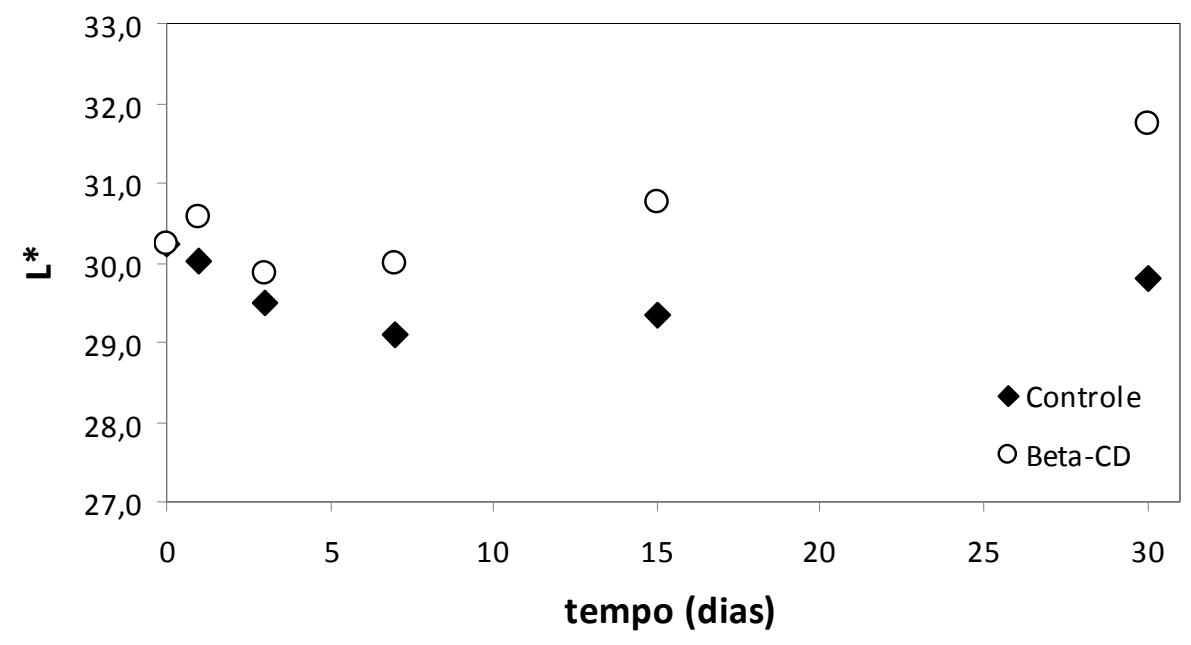

Figura 1 - Coordenada $L^{*}$ dos néctares de maracujá armazenados a temperatura ambiente por 30 dias.

Com relação a coordenada a* (Figura 2), este parâmetro se manteve praticamente constante para a amostra controle durante a primeira quinzena de armazenamento, sofrendo uma redução significativa após este período. Para o néctar enriquecido com $\beta-\mathrm{CD}$, esta redução na cor foi visível após a primeira semana de estocagem.

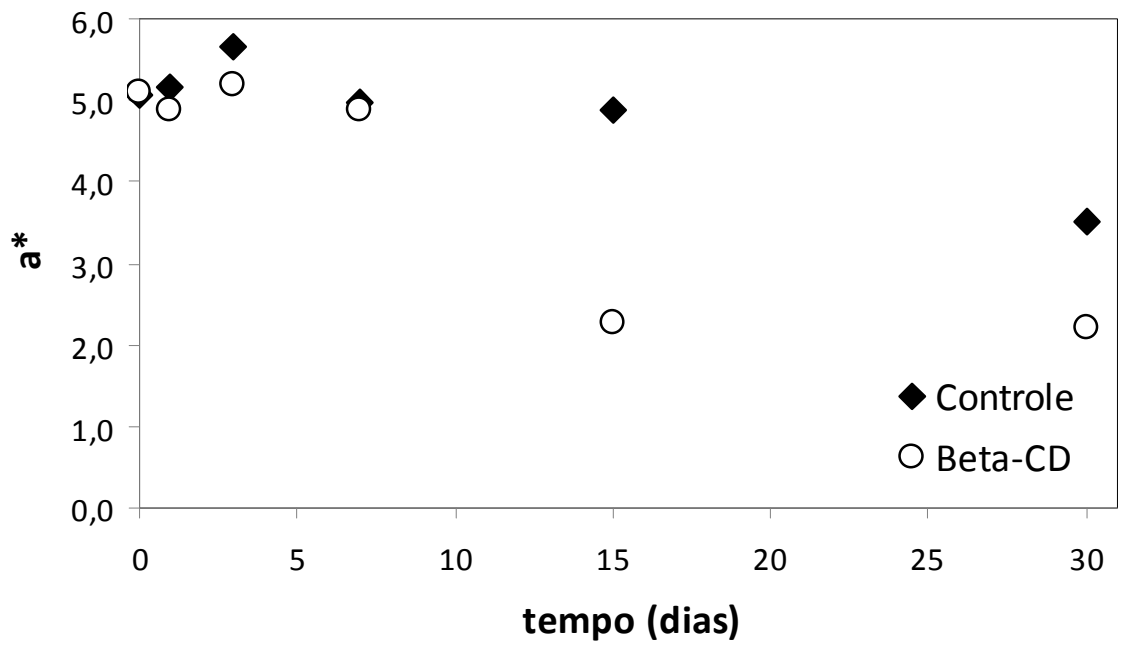

Figura 2 - Coordenada a* dos néctares de maracujá armazenados a temperatura ambiente por 30 dias. 


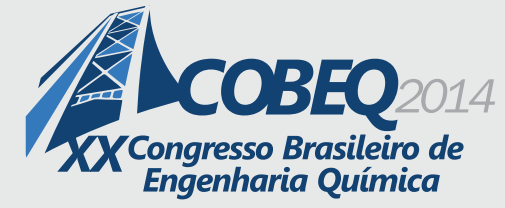

As cromaticidades $\mathrm{a}^{*} \mathrm{e} \mathrm{b}^{*}$ podem ser relacionadas com os teores de carotenóides presentes no néctar de maracujá, pois estes são corantes naturais responsáveis pelo espectro de cores, que varia do vermelho ao amarelo (Rodriguez-Amaya et al., 2008). A redução na coordenada a* indicou que o tempo de estocagem provocou a degradação dos carotenóides da cor vermelha para a amarela, sendo mais significativa para a amostra enriquecida com $\beta$-CD. Além disso, a degradação dos carotenóides vermelhos presentes no néctar, deixou a amostra mais amarelada e, portanto mais clara, como pode ser observado na Figura 1, com o aumento da luminosidade da amostra enriquecida com $\beta$-CD.

O mesmo comportamento foi observado para a coordenada $b^{*}$, com uma redução mais acentuada deste parâmetro para o néctar enriquecido $\operatorname{com} \beta-C D$.

Talcott et al. (2003) relatam que a presença de ácido ascórbico em blends de suco causa um efeito protetivo dos carotenóides. Esta proteção oxidativa dos carotenóides pelo ácido ascórbico pode ser atribuída à proteção oxidativa direta ou reações de isomerização. Analisando as Figuras 1 e 2, pode-se observar este efeito na amostra controle, com a redução da luminosidade na primeira semana de armazenamento, provavelmente devido a oxidação do ácido ascórbico, e posterior redução na coordenada $\mathrm{a}^{*}$, devido a degradação dos carotenóides vermelho para amarelo. Com relação a amostra enriquecida com $\beta-\mathrm{CD}$, a oxidação dos carotenóides foi mais rápida, quando comparada com a amostra controle (Figura 2), com a redução da coordenada a* após a primeira semana de armazenamento, sugerindo uma possível formação de complexo de inclusão do ácido ascórbico do néctar com a $\beta-\mathrm{CD}$, protegendo-o da oxidação. Este fato também pode ser notado na Figura 1, em que a luminosidade da amostra enriquecida com $\beta$-CD se manteve praticamente constante na primeira semana de armazenamento, devido a redução da oxidação do acido ascórbico.

Com relação ao teor de pró-vitamina A (Figura 3), a sua redução foi mais significativa para a amostra enriquecida com $\beta-\mathrm{CD}$, do que para a amostra controle, um resultado já esperado, devido a redução da coordenada a* (Figura 2) dos néctares analisados. Na primeira quinzena de armazenamento a redução de pró-vitamina A foi de $10 \%$ para a amostra enriquecida com $\beta$-CD, enquanto para a mostra controle esta redução foi de $5 \%$. Navarro et al. (2011a) determinaram perdas de 5 a $6 \%$ no conteúdo de pró-vitamina A de suco de mandarim enriquecido com casca de romã e goji berries, para a amostra controle e amostra adicionada de $\beta$-CD, respectivamente, durante 75 dias de armazenamento a $4^{\circ} \mathrm{C}$. Os autores afirmam que a adição de $\beta$-CD no suco e a estocagem refrigerada afetaram negativamente o total de carotenóides e, portanto a pró-vitamina $\mathrm{A}$. 


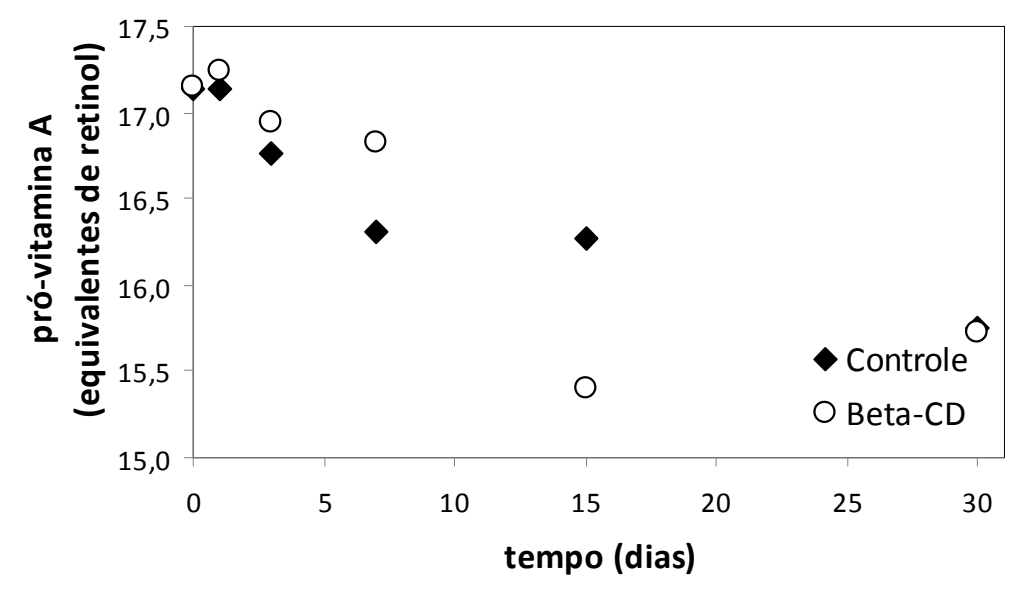

Figura 3 - Conteúdo de pró-vitamina A dos néctares de maracujá armazenados a temperatura ambiente por 30 dias.

\section{CONCLUSÃO}

O enriquecimento do néctar de maracujá com $\beta$-CD não implicou numa melhora significante na estabilidade a estocagem deste produto. Análises de $\mathrm{pH}$, acidez titulável e cor indicaram uma maior degradação dos carotenóides com a adição de $\beta$-CD e o tempo de estocagem. Este fato pode estar relacionado com uma possível formação do complexo de inclusão do ácido ascórbico do néctar com a $\beta-\mathrm{CD}$, protegendo-o da oxidação e, consequentemente, acelerando a degradação dos carotenóides. Maiores estudos com o uso da $\beta$ $\mathrm{CD}$ na estabilidade do ácido ascórbico do néctar de maracujá devem ser realizados para comprovar esta suposição.

\section{REFERÊNCIAS}

BRANCO, I. G.; SANJINEZ-ARGANDOÑA, E. J.; SILVA, M. M.; PAULA T. M. Avaliação sensorial e estabilidade físico-química de um blend de laranja e cenoura. Ciência $e$ Tecnologia de Alimentos, v. 27, n. 1, p. 7-12, 2007.

COELHO. A. A.; CENCI. S. A.; RESENDE. E.D. Qualidade do suco de maracujá-amarelo em diferentes pontos de colheita e após o amadurecimento. Ciência e Agrotecnologia, v. 34, n 3, p. 722-729, 2010.

IAL - Instituto Adolfo Lutz. Métodos Físico-Químicos para Análise de Alimentos. $4^{\mathrm{a}}$ edição. $1^{\mathrm{a}}$ Edição Digital. São Paulo-SP. 2005.

MELÉNDEZ-MARTÍNEZ, A. J. Estudio de los carotenoides y del color de zumos de naranja. $\mathrm{Ph}$. D. Thesis, University of Seville, Spain, 2005.

MORZELLE, M. C.; SOUZA, E. C.; ASSUMPÇÃO, C. F.; FLORES, J. C. J.; OLIVEIRA, K. A. M. Agregação de valor a frutos de ata através do desenvolvimento de néctar misto de 
maracujá (Passiflora Edulis Sims) e ata (Annona Squamosa L.) Alimentos e Nutrição, Araraquara, v 20, n 3, p. 389-393, jul/set 2009.

NAVARRO, P.; NICOLAS, T. S.; GABALDON, J. A.; MERCADER-ROS, M. T.; CALÍNSÁNCHEZ, Á.; CARBONELL-BARRACHINA, Á.; PÉREZ-LÓPEZ, A. Effects of cyclodextrin type on vitamina $\mathrm{C}$, antioxidant activity, and sensory attibutes of a Mandarim juice enriched with pomegranate and Goji berries. Journal of Food Science, v 76, n 5, p 319-324, 2011a.

NAVARRO, P.; MELENDEZ-MARTINEZ, A. J.; HEREDIA, F.; GABALDON, J. A.; CARBONELL-BARRACHINA, Á. A.; SOLER, A.; PÉREZ-LÓPEZ, A. J. Effects of $\beta$ cyclodextrin addition and farming type on vitamina $\mathrm{C}$, antioxidant activity, carotenoids profile, and sensory analysis in pasteurized orange juices. International Journal of Food Science \& Technology, v 46, p 2182-2190, $2011 \mathrm{~b}$.

ÖZOGLU, H.; BAYMDIRH, A. Inhibition of enzymatic browing in cludy apple juice with selected antibrowning agents. Food Control, v. 13, p 213-221, 2002

RODRIGUEZ-AMAYA, D. B.; KIMURA, M.; AMAYA-FARFAN, J. Fontes brasileiras de carotenóides - Tabela brasileira de composição de carotenóides em alimentos, Ministério do Meio Ambiente, 2008.

SANDI, D.; CHAVES, J. B. P.; SOUSA, A. C. G.; PARREIRAS, J. F. M.; SILVA, M. T. C.; CONSTANT, P. B. L. Hunter color dimensions, sugar content and volatile compounds in pasteurized yellow passion fruit juice (Passiflora edulis var. flavicarpa) during storage. Brazilian Archives of Biology and Technology, v. 47, n. 2, p. 233-245, 2004.

SZENTE, L.; SZEJTLI, J. Cyclodextrins as food ingredients. Trends in Food Science \& Technology, v. 15, n. 3, p. 137-142, 2004.

TAlCOTT, S. T.; PERCIVAL, S. S.; PITTET-MOORE, J.; CELORIA, C. Phytochemical composition and antioxidant stability of fortified yellow passion fruit (Passiflora edulis). Journal of Agricultural and Food Chemistry, v. 51, n. 4, p. 935-941, 2003. 